\title{
Simulating Storm Surge and Inundation Along the Taiwan Coast During Typhoons Fanapi in 2010 and Soulik in 2013
}

\author{
Y. Peter Sheng ${ }^{1, *}$, Vladimir A. Paramygin ${ }^{1}$, Chuen-Teyr Terng ${ }^{2}$, and Chi-Hao Chu ${ }^{2}$ \\ ${ }^{1}$ University of Florida, Gainesville, Florida, U.S.A. \\ ${ }^{2}$ Central Weather Bureau, Taipei City, Taiwan, R.O.C.
}

Received 10 January 2016, revised 9 June 2016, accepted 13 June 2016

\begin{abstract}
Taiwan is subjected to significant storm surges, waves, and coastal inundation during frequent tropical cyclones. Along the west coast, with gentler bathymetric slopes, storm surges often cause significant coastal inundation. Along the east coast with steep bathymetric slopes, waves can contribute significantly to the storm surge in the form of wave setup. To examine the importance of waves in storm surges and quantify the significance of coastal inundation, this paper presents numerical simulations of storm surge and coastal inundation during two major typhoons, Fanapi in 2010 and Soulik in 2013, which impacted the southwest and northeast coasts of Taiwan, respectively. The simulations were conducted with an integrated surge-wave modeling system using a large coastal model domain wrapped around the island of Taiwan, with a grid resolution of 50 - 300 m. During Fanapi, the simulated storm surge and coastal inundation near Kaohsiung are not as accurate as those obtained using a smaller coastal domain with finer resolution $(40-150 \mathrm{~m})$. During Soulik, the model simulations show that wave setup contributed significantly (up to 20\%) to the peak storm surge along the northeast coast of Taiwan. Three-D model simulations yield more accurate water level results and significant vertical variations in horizontal velocity at stations where wave-surge interaction is more pronounced. The simulated storm surge generally agreed well with the observed data at nearly 40 stations.
\end{abstract}

Key words: Storm surge, Coastal inundation, Numerical simulation, Fanapi, Soulik, Taiwan

Citation: Sheng, Y. P., V. A. Paramygin, C. T. Terng, and C. H. Chu, 2016: Simulating storm surge and inundation along the Taiwan coast during typhoons Fanapi in 2010 and Soulik in 2013. Terr. Atmos. Ocean. Sci., 27, 965-979, doi: 10.3319/TAO.2016.06.13.01(Oc)

\section{INTRODUCTION}

More than $75 \%$ of the world's population lives within 100 miles from the coastline. Coastal communities and ecosystems around the world are subjected to increasing hazard from storm surge and coastal inundation due to tropical cyclones as well as climate change and sea level rise. This is compounded by growing coastal population and development. Along the coast of Taiwan, frequent tropical cyclones often cause storm surges and coastal inundation that damages properties and threatens lives. The impact of tropical cyclones on the coastal regions in Taiwan depend on the tropical cyclone characteristics and coastal region characteristics. For example, along the southwest coast of Taiwan with low elevation and gentler bathymetric slope, major flooding often occurs due to storm surge during tropi-

\footnotetext{
* Corresponding author

E-mail:pete.pp@gmail.com
}

cal cyclones. Typhoon Fanapi caused major flooding along the southwest coast of Taiwan in September 2010. Along the rocky northeast coast of Taiwan where the bathymetric slope is steep, waves often break very close to the coastline and contribute significantly to the storm surge. During July 2013, Typhoon Soulik caused significant storm surges and waves along the northeast coast of Taiwan. The tracks of Fanapi and Soulik provided by Central Weather Bureau (CWB) are shown in Fig. 1.

Numerous storm surge studies have been conducted around Taiwan using a number of different storm surge models, e.g., CWB-1 model (Yu et al. 1994), CWB-2 model (Wu 2014), TORI (Taiwan Ocean Research Institute) model (Liau and Chen 2015), and HMTC (Harbor and Marine Technology Center) model (Lee et al. 2015). According to a review by Sheng (2015), these models are all two-dimensional models. Most models did not include wave effects and coastal 
inundation simulations. In addition, the grid resolution of the CWB-1 and CWB-2 are relatively coarse (> $200 \mathrm{~m})$. These factors contributed to the relatively large errors in the storm surge simulation during recent typhoones including Fanapi in 2010 and Soulik in 2013. This paper uses an integrated storm surge modeling system (Sheng et al. 2010a, b) to simulate storm surge and coastal inundation during two major typhoons, Fanapi in 2010 and Soulik in 2013. The simulations use a large coastal model domain wrapped around the island of Taiwan with a grid resolution of $50-300 \mathrm{~m}$. These simulations are aimed to quantify coastal inundation along the southwest coast and the effect of waves on storm surges along the northeast coast. Simulations were conducted using a smaller coastal domain with a finer resolution (40-150 m) near the Kaohsiung coastal region, where more detailed data are available, to eveluate the model resolution effect simulated storm surge and innundation.

While this study focues on the storm surge, waves, and inundation induced by Fanapi and Soulik around Taiwan, a recent study by Ko et al. (2016) studied the impact of Fanapi and tides on coastal upwelling and circulation around Taiwan. Their study found that, on its way to Taiwan, Fanapi induced a cold wake spreading preferably on the right side of the essentially westward running track in the western Pacific. The three upwelling areas in the East China Sea and Taiwan Strait subsequently became expansive as Fanapi approached and entered the Taiwan Strait. They suggested using high model resolution for further typhoon and tides effects on upwelling elucidation. Therefore, our high-resolution modeling and their larger scale modeling can complement each other in future study on the effects of typhoon and tides on coastal upwelling and circulation.

\subsection{Typhoon Fanapi: Meteorological History}

The tropical depression that struck parts of Taiwan and Mainland China formed on early 14 September 2010. On the same day, this depression was upgraded into a Tropical storm, receiving the name Fanapi. The system then developed into a severe tropical storm, and then into a typhoon. By 18 September, it reached its peak intensity. It made its first landfall at Hualien County Taiwan at 8:40 a.m. on 19 September. Upon reentering the ocean (Taiwan Strait), Fanapi weakened into a severe tropical storm. It continued to maintain its strength before making a second landfall at Zhangpu County, Zhangzhou in Fujian province, Mainland China. It then lost strength again and dissipated on 22 September.

In Taiwan the floods affected downtown Kaohsiung, including the Sanmin, Nanzih, Zuoying, and Gushan districts. The total damage was estimated at US\$211 million with agricultural losses over $\$ 65$ million USD while causing two direct and three indirect deaths. Significant storm surge was observed near the coast of Kaohsiung (JTWC 2010, 2011).

\subsection{Typhoon Soulik: Meteorological History}

Typhoon Soulik formed and consolidated during 6 - 8 July 2013, attaining its peak intensity of $925 \mathrm{mb}$ on 10 July. At this time it was classified as Category 4 on the SaffirSimpson scale with one minute sustained winds of $145 \mathrm{mph}$. According to the CWB, Soulik struck Taiwan on 12 July near Yilan City in northern Taiwan with winds as high as $120 \mathrm{mph}$ and gusts as high as $140 \mathrm{mph}$. Once over land it quickly lost intensity, but retained typhoon strength during its crossing of the island. Winds up to $75 \mathrm{mph}$ buffeted Taipei, tearing roofs off buildings, downing power lines and snapping or uprooting trees. At the height of the storm, roughly 800000 residences were without power. Torrential rains, amounting to 35 inches in Bailan, accompanied the destructive winds. Across the island, four people were killed by the storm and 123 people were injured in various incidents. Substantial damage took place within the agricultural sector, with losses estimated in excess of US $\$ 42.55$ million. Overall damage caused by the storm exceeded US\$557 million (JTWC 2014).

Previous studies (Wu 2014) used the CWB-2 model and Liau and Chen (2015) used the TORI model to simulate Typhoon Soulik (2013) with limited success. While it seemed that the tidal components were well captured the storm surge peaks were generally under predicted. $\mathrm{Wu}$ did not include wave setup in the model simulation and his results significantly underestimated the surges at many stations and particularly at Longdong along the northeast coast. While Liau and Chen (2015) included wave setup thourgh one-way surge and wave model coupling, their results still deviated significantly from the measured data. The

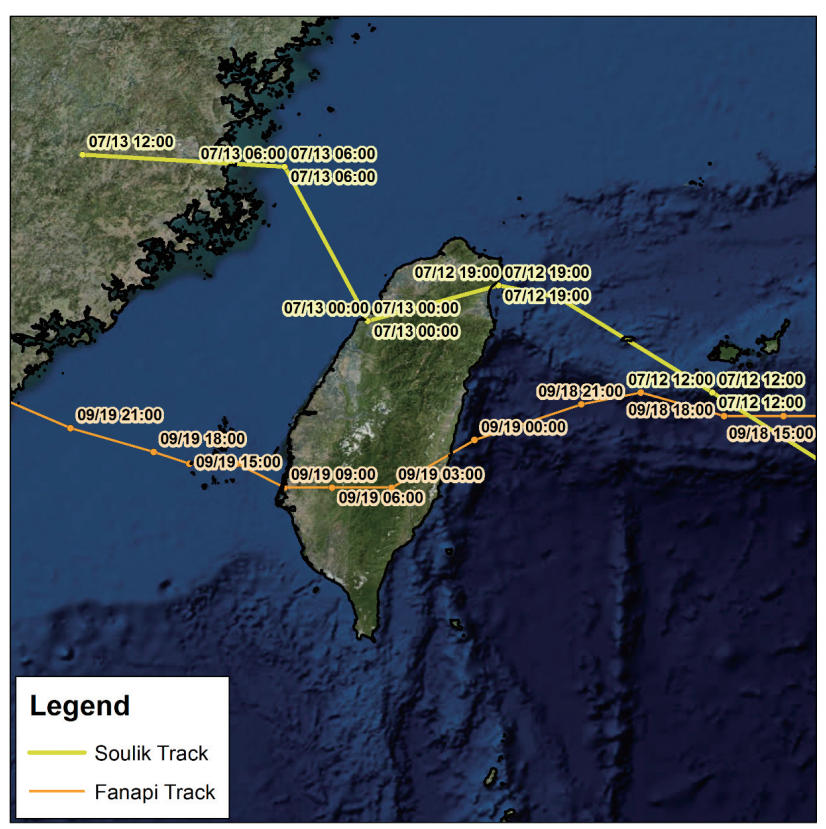

Fig. 1. Best tracks of Typhoons Fanapi (2010) and Soulik (2013) provided by CWB passing over Taiwan. (Color online only) 
simulation errors were generally larger at locations close to the typhoon tracks.

\section{NUMERICAL MODEL AND SETUP}

This study uses the Advanced Coastal Modeling System (ACMS, see Fig. 2) which is an integrated storm surge modeling system (Sheng et al. 2006, 2008, 2010a, b; Sheng and Liu 2011; Tutak and Sheng 2011) built upon the CH3D (Curvilinear-grid Hydrodynamics in 3D) circulation model (Sheng 1987, 1990). The CH3D model solves the continuity equation and the horizontal momentum equations in nonorthogonal boundary-fitted horizontal coordinates and a sigma coordinate system in the vertical dimension, making it suitable for complex coastal zone applications. CH3D can be run in both $3 \mathrm{D}$ and $2 \mathrm{D}$ vertically integrated modes. A robust turbulence closure model (Sheng and Villaret 1989) is used to represent vertical mixing, while horizontal mixing is represented with Smagorinsky type mixing coefficients. A flooding and drying algorithm based on an enhanced version of Davis and Sheng (2003) is included in the model to enable accurate storm surge and inundation simulation. At the air-sea interface, the shear stress is produced by wind as well as waves, while at the bottom, current-wave interaction produces enhanced bottom stress. Detailed motion and boundary condition equations are described in Sheng et al. (2010a).

The ACMS has the capability of using a variety of wind fields and related boundary conditions as forcing, including the GFDL (Geophysical Fluid Dynamics Laboratory) model (Kurihara et al. 1998), NOAA (National Oceanic and Atmospheric Administration)/HRD (Hurricane Research Division) H* (e.g., DiNapoli et al. 2012), NAM (North Atlantic Mesoscale) model which is basically the WRF (Weather Research and Forecast) model operated by the National Center for Environmental Prediction (NCEP) at the U.S., NOGAPS (Navy Operational Global Atmospheric Prediction System, see Rosmond 1992), Advanced
Research WRF model (http://www2.mmm.ucar.edu/wrf/ users/docs/user_guide_V3/contents.html), TWRF (Hsiao et al. 2010, 2012) etc. In addition, the ACMS includes a wind processing module that features several synthetic wind models such as a symmetric analytical wind model, developed by Wilson (1960), Holland (1980), and an asymmetric wind model (Xie et al. 2006). The wind processing module also has the capability to add wind dissipation due to land roughness based on land cover data (IPET 2006; Sheng et al. 2010b), and wind data assimilation.

In the ACMS, the CH3D model is dynamically coupled to the SWAN (Simulating WAves Nearshore) wave model model (Ris et al. 1999): wave results obtained by SWAN are passed to the CH3D and water depths and currents obtained by the CH3D model are passed onto SWAN. This allows accounting for wave setup and wave-current interaction within the CH3D model, which features several formulations for calculating wave stresses, including vertically varying formulations (e.g., Mellor 2008) as well as the vertically uniform formulation of Longuet-Higgins and Stewart $(1962,1964)$. For simplicity, however, vertically uniform wave stress formulation is used in this study.

The ACMS uses a high resolution horizontal grid that can vary from $20-30 \mathrm{~m}$ near the coast to a few hundred meters in offshore areas. Because it uses an efficient implicit/semi-implicit algorithm to resolve surface gravity wave propagation, $\mathrm{CH} 3 \mathrm{D}$ allows the use of relatively large time steps $(1-60 \mathrm{~s})$. To maintain high efficiency in CH3D simulations, a high resolution grid is usually used only in the coastal domain, which extends from the coastline to $50-100 \mathrm{~km}$ offshore. The coastal domain is usually coupled to a basin scale (large scale) domain which covers all or part of a large basin, e.g., the Gulf of Mexico, or the Northwest Pacific Ocean, which can be simulated using a variety of ocean circulation models, e.g., CH3D, NCOM (Navy Coastal Ocean Model) (Barron et al. 2004), HYCOM (HYbrid Coordinate Ocean Model) (Bleck and Benjamin 1993) etc. While NCOM and HYCOM do not simulate tides, CH3D

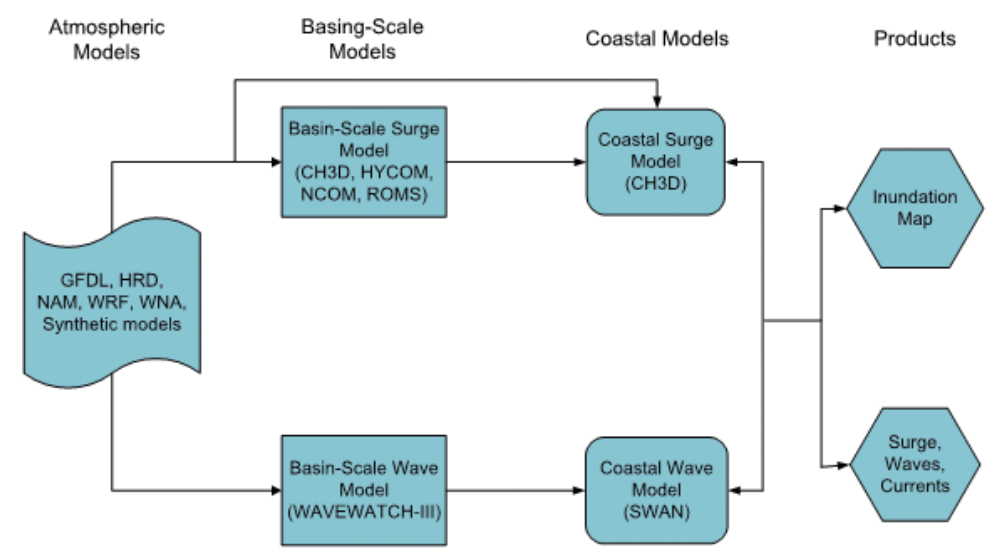

Fig. 2. ACMS modeling system diagram. (Color online only) 
can be used to simulate both tides and storm surge during typhoons in the coastal domain.

ACMS, which is also known as CH3D-SSMS (CH3DStorm Surge Modeling System), has been compared to other storm surge models including ADCIRC (ADvanced CIRCulation Model; Luettich et al. 1992), POM (Princeton Ocean Model; Peng et al. 2004), FVCOM (Finite Volume Coastal Ocean Model; Chen et al. 2006), and SLOSH (Sea, Lake, and Overland Surges from Hurricanes; Jelesnianski et al. 1992). Detailed comparison of models (Sheng et al. 2012) were made in terms of simulated storm surges during historic storms as well as coastal inundation maps including the surge atlas and the $1 \%$ annual chance coastal inundation maps which is also known as the Base Flood Elevation (BFE) according to the Federal Emergency Management Agency (FEMA) of the US (NAS 2009).

\subsection{Model Domains}

For ACMS simulations, this study uses two computational domains with non-orthogonal boundary fitted grids which differ in area covered and horizontal resolution. The larger domain TW, as shown in Fig. 3, covers the entire Taiwan Island coastline, containing 2 million grid cells with an average grid cell size of $\sim 150 \mathrm{~m}$ but a minimum grid of $50 \mathrm{~m}$. The smaller domain TW-KS, as shown in Fig. 4, covers the southwestern coast centered around Kaohsiung and features an average cell size of about $100 \mathrm{~m}$ with cell sizes as fine as $40 \mathrm{~m}$ in near shore and inland areas with a total count of 240000 grid cells.

These two computational domains are nested inside a large rectangular domain TW500, as shown in Fig. 5, with $500 \mathrm{~m}$ by $500 \mathrm{~m}$ grid resolution, which provides boundary conditions to the TW and TW-KS domains. The TW500 domain is always run in 2D mode and is only forced by wind and pressure fields and does not include the tide effects.

Bathymetry and topography for the model domain are derived from two datasets: one data set having $500 \mathrm{~m}$ resolution and providing elevations over ocean and land and the second one having $40 \mathrm{~m}$ resolution and providing land elevation over limited area near Kaohsiung. CH3D model uses sigma vertical coordinates and 3D simulations discussed in this paper are carried out using four vertical sigma layers.

The data stations located over the Taiwan coastline are shown in Fig. 6. For simplicity, selected model results at only a number of select stations where storm surge effects are most prominent are shown and discussed.

\subsection{Initial Conditions}

Numerical simulations are started with water level located at the mean sea level and a 3-day spin-up time allows tides to fully develop and properly initialize the water level before the storm reaches the model domain.

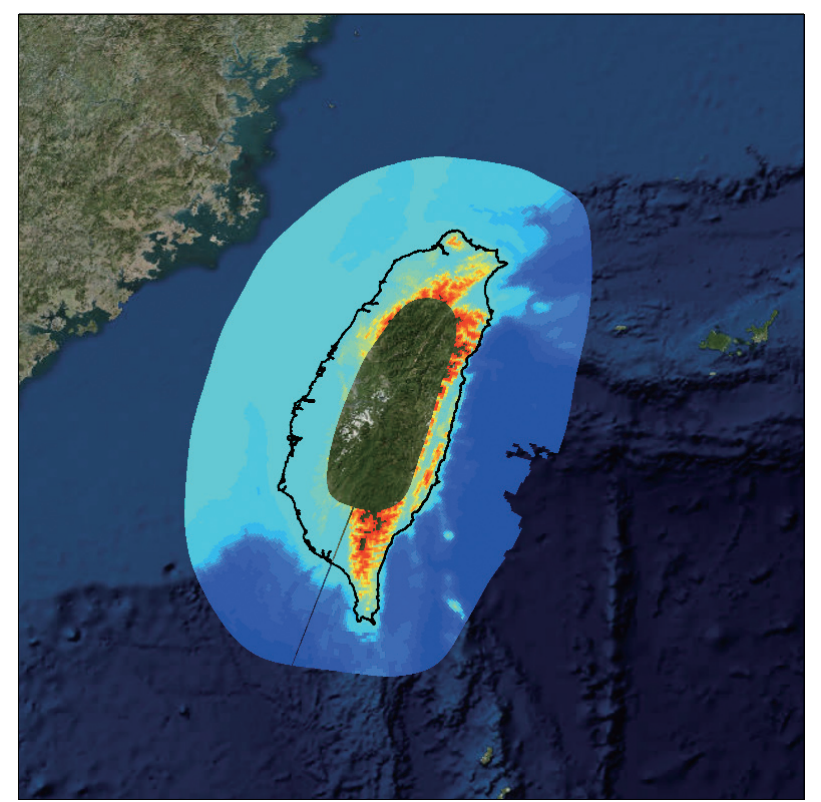

Fig. 3. ACMS TW computational domain. (Color online only)

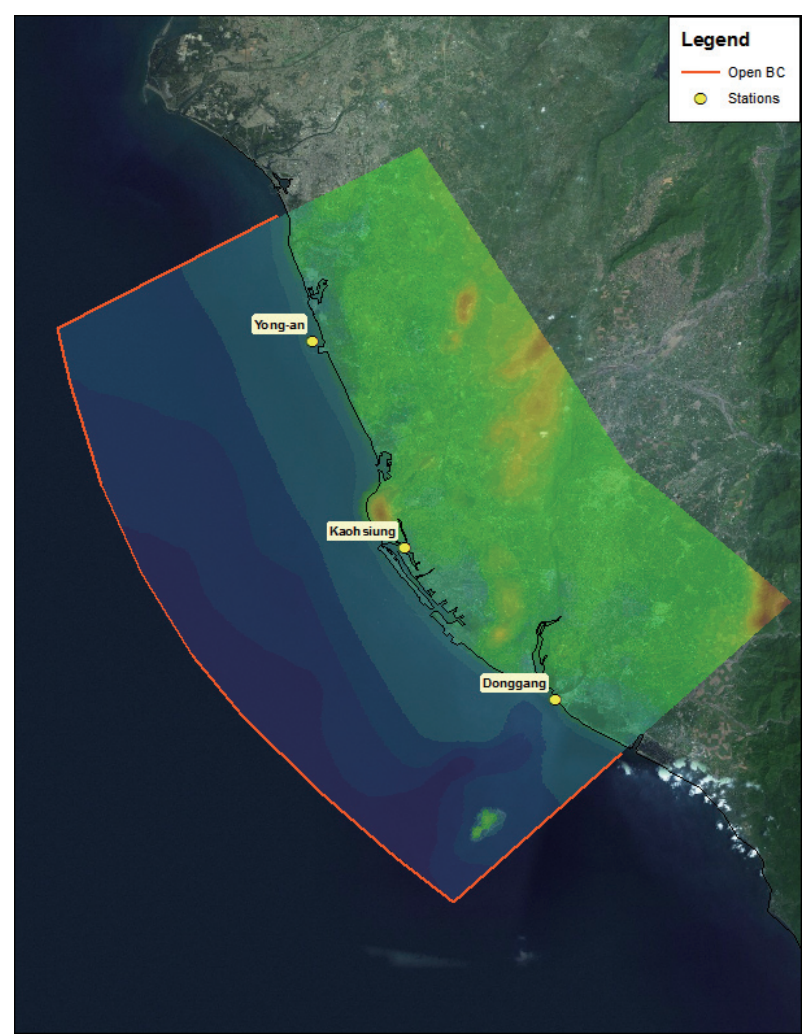

Fig. 4. ACMS TW-KS (Kaohsiung) computational domain. (Color online only) 


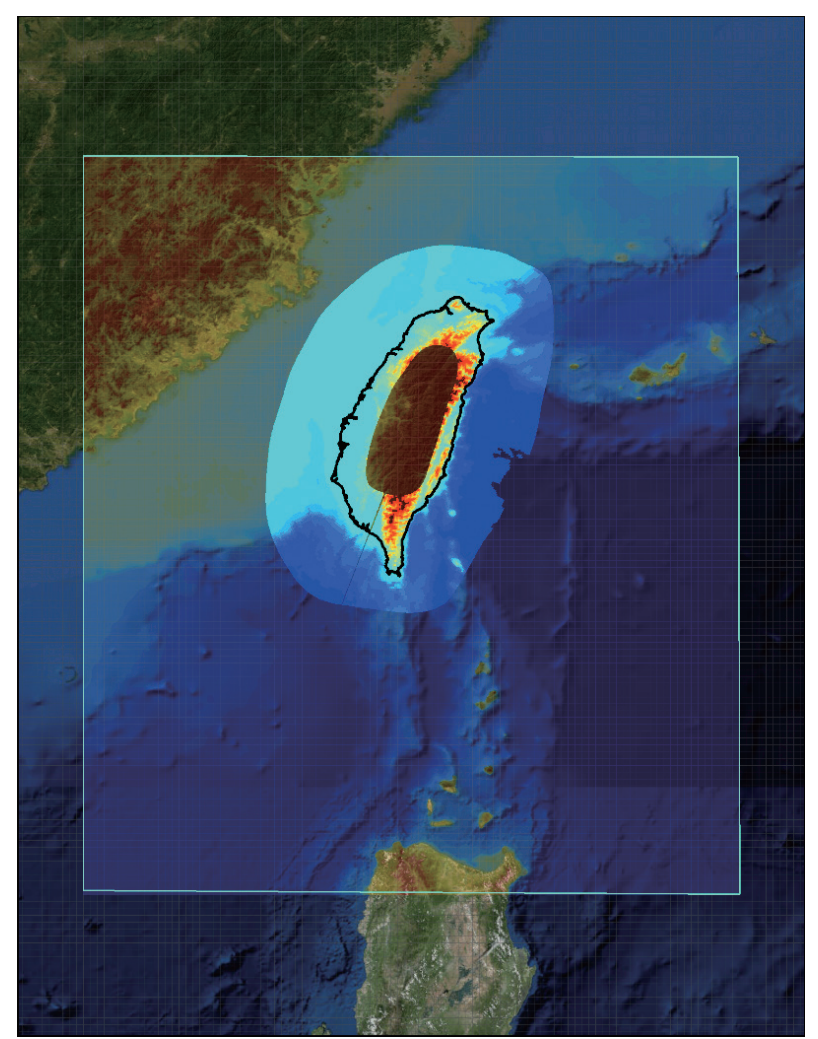

Fig. 5. ACMS TW500 domain (outlined in bright yellow) with TW domain (outlined in green) and TW-KS domain (outlined in red) nested inside.

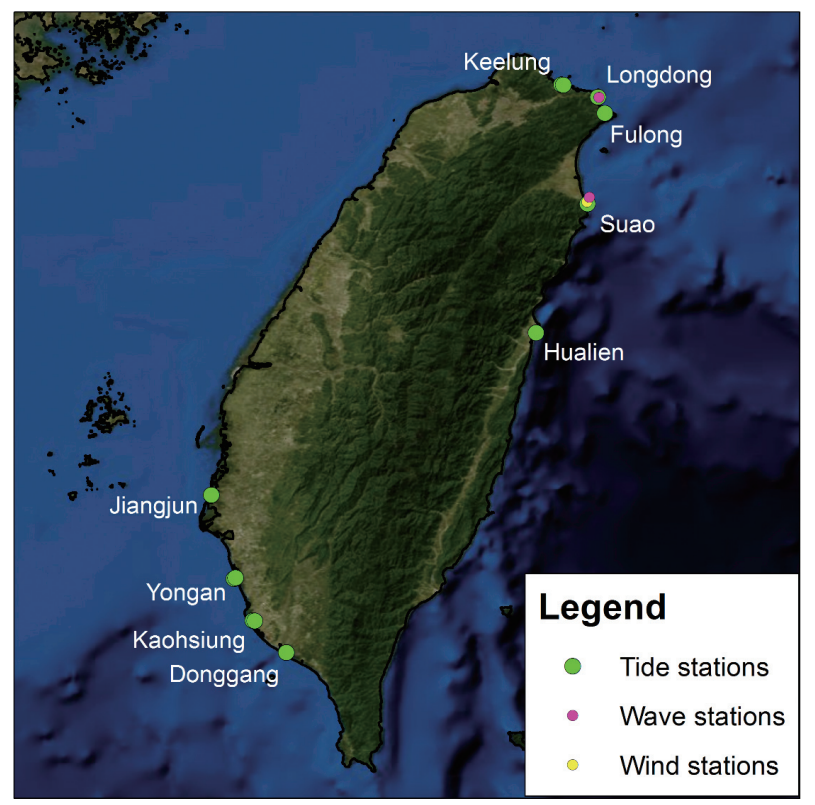

Fig. 6. Locations of data stations.

\subsection{Boundary Conditions}

The water level at the open boundary of the TW and the TW-KS domains consists of two components - surge and tides. The surge along the open boundary are simulated water level from the TW500 domain. TW500 model simulations are always done in 2D and are only forced by wind and sea level air pressure (tides are not included).

Along the open boundary of TW and TW-KS, tidal constituents are extracted from the TPXO model and the following constituents are used:

(1) Primary: M2, S2, N2, K2, K1, O1, P1, Q1

(2) Long period: Mf, Mm

(3) Non-linear: M4, MS4, MN4

These constituents are locally adjusted to provide a better fit to local data. Tides are verified by running a no-wind scenario and comparing simulated tides against the prediction values (only five major constituents: K1, M2, N2, O1, $\mathrm{S} 2$ are verified) against measured data and verification results are displayed in Fig. 7.

Wave boundary conditions at the open boundary are drawn from SWAN results on the TW500 domain.

To examine the impact of large scale circulation on coastal currents during typhoons, it is possible for our model to use the results from the large scale ocean circulation model (e.g., Ko et al. 2016) as open boundary conditions.

\subsection{Wind Forcing}

This study used three different wind models (Fig. 8) to force the coastal modeling system:

(1) An analytical parametric wind model with some modifications from Xie et al. (2006). This model is driven by such storm parameters as: location of the center of the storm, central pressure, maximum wind speed, and several radii to constant wind. Four radii are defined for each constant wind contour (one for each quadrant) giving the wind field an assymetric shape. The wind field is then calculated as a function that is fit to these parameters. All parameters are obtained from best tracks provided by the CWB and the US Navy Joint Typhoon Warning Center.

(2) An analytical parametric wind model originaly designed by Holland (1980). This model is also driven by parameters from the best track, but the wind field is defined using the following parameters: location of the storm center, pressure in the center of the storm, translational speed of the storm, maximum wind speed, and the radius to maximum wind. All parameters are obtained from best tracks provided by the CWB and the US Navy Joint Typhoon Warning Center.

(3) The WRF model (e.g., Skamarock et al. 2005; Hsiao et al. 2010) which is a next-generation mesoscale numerical weather prediciton system. Wind snapshots output 
from the TWRF model at 6-hour intervals provided by the CWB (Hsiao et al. 2010) were used to define the wind forcing.

For parametric wind models, wind dissipation by land cover and land use features is usually applied to the wind profiles, following the procedure described in Interagency Performance Evaluation Task Force (IPET 2006) and Sheng et al. (2010b). However, due to lack of high resolution land data for this study, the detailed land dissipation procedure is not used. Instead, a simplified dissipation procedure is applied to the wind fields by only differentiating between two classes: sea and land. A future study will include high resolution tiopography.

When parametric wind models are used, wind fields are updated at every model timestep. For the WRF-driven model runs, wind fields are interpolated using a method that takes into account the position of the storm from 6-hourly wind fields (see, e.g., Sheng et al. 2010a).

While wind data is limited, especially given the fact that models use wind at $10 \mathrm{~m}$ elevation but available observed data is at $1-5 \mathrm{~m}$ elevation, an adjustment is needed to compare the simulated to observed data (Fig. 9).
The model results included in this paper use wind forcing from the Xie et al. (2006) model. However, it should be noted that, while there are some differences in simulated results, the overall performance was reasonably comparable for all three wind fields. While wind data in adjacent coastal areas may be available from other sources, they were not measured at the $10 \mathrm{~m}$ level and have different format, hence a detailed comparison of wind models vs. wind data will be the topic of a future paper.

\subsection{Precipitation Data}

Both Fanapi and Soulik brought heavy rain to the area and therefore precipitation was a considerable source of flooding inland and needs to be included into the model. Figure 10 shows the rain fall time-series during Fanapi as observed in the Kaohsiung area. However, the precipitation effect in the model is limited to the span of the computational domain. Since the model does not cover areas that are located well inland, the rainfall and resultant runoff that originate outside of the model domain are not included in the model. For future study, we will consider coupling our (a)

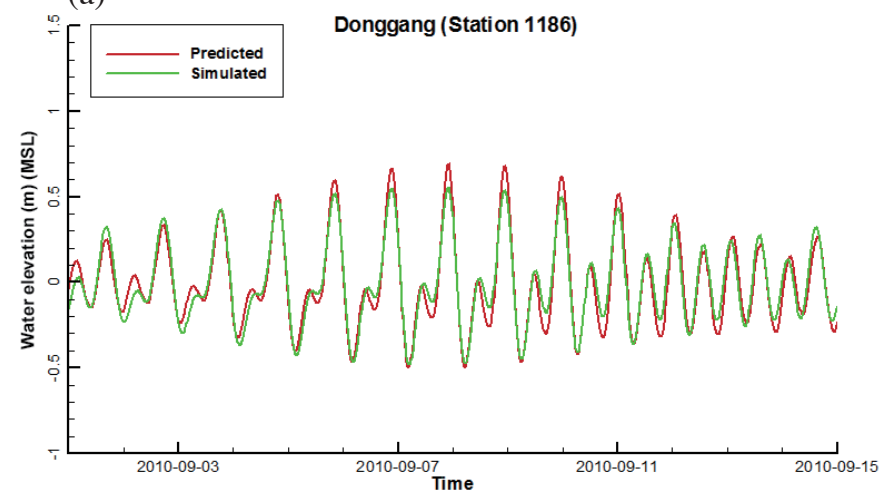

(b)

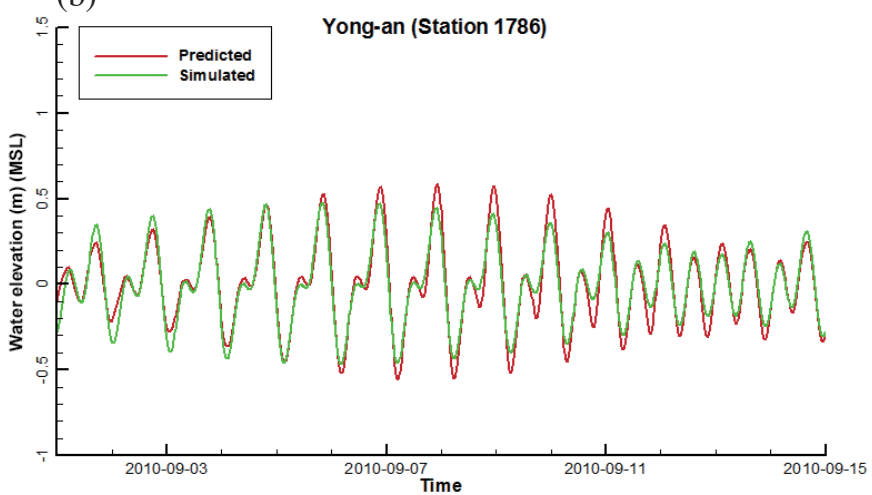

Fig. 7. Simulated vs. measured tides at (a) Donggang and (b) Yong An.

(a)

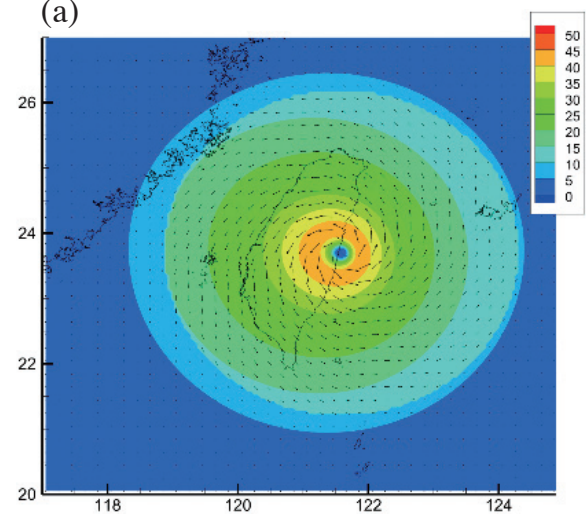

(b)

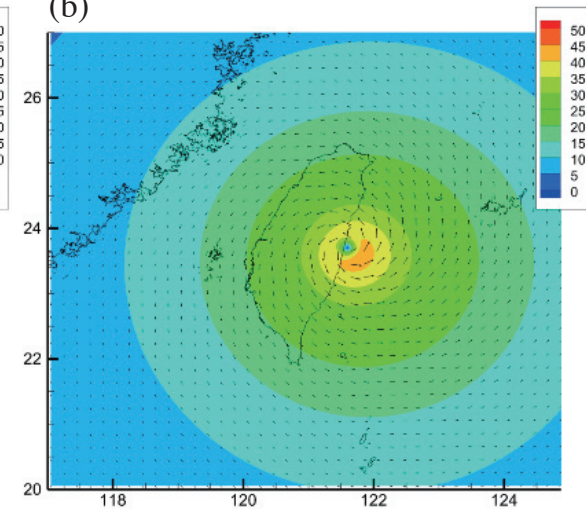

(c)

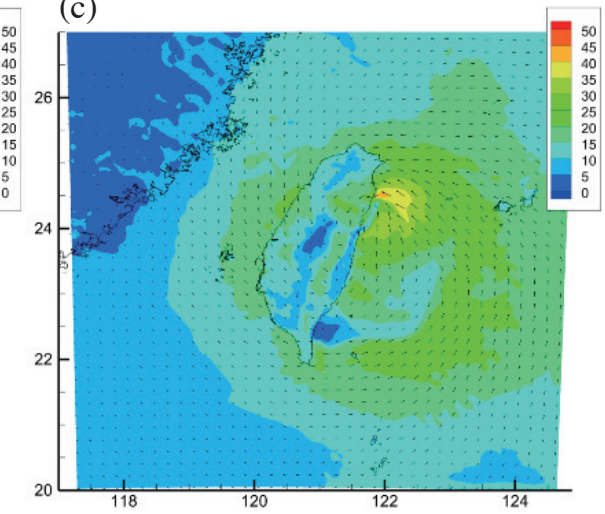

Fig. 8. Three wind field snapshots from (a) Xie, (b) Holland, and (c) TWRF models at 00:00 09/13/2010 as Typhoon Fanapi makes landfall on the east coast of Taiwan. 


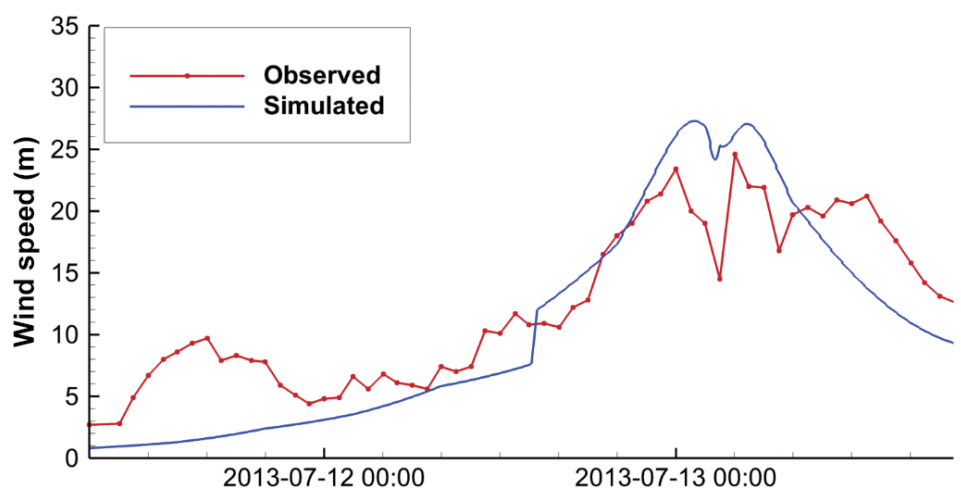

Fig. 9. Comparison of simulated (by the asymmetric Xie model) and observed wind during Typhoon Soulik at station 46706A, located near Suao. Note that model wind data was adjusted using log law due to the fact that model uses wind at $10 \mathrm{~m}$ level but observed data was recorded at $2 \mathrm{~m}$. (Color online only)

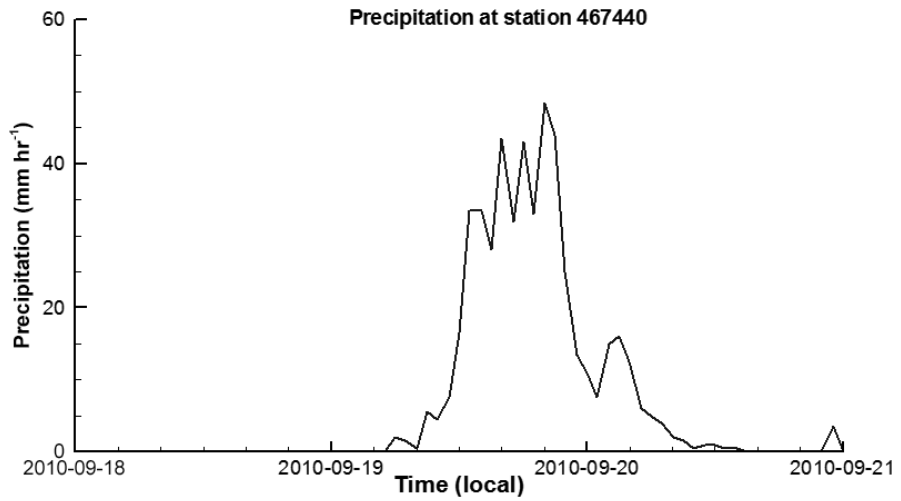

Fig. 10. Measured precipitation data at CWB weather station 467440 located at Kaohsiung during Typhoon Fanapi.

model with a watershed model that could provide such information as a boundary condition.

\subsection{Model Parameters}

CH3D model runs in 2D and 3D modes are made. The 2D model uses Manning's bottom friction formulation with the Manning's $n=0.025$. The 3D model uses 4 vertical sigma layers and a bottom roughness $Z_{0}=0.4 \mathrm{~cm}$. As explained in Lapetina and Sheng (2015), these values are typical values for storm surge model simulations.

The model uses a 30-s time step.

\section{MODEL RESULTS}

The main set of model simulations were done using a coupled surge-wave system including tides and wind and using a 3D version of the CH3D model.

\subsection{Tides}

As an example, model simulated tides at two stations near Kaohsiung during Typhoon Fanapi in 2010 are shown in Fig. 7. In general, tides are well simulated by the model with less than 5 - 10\% root-mean-square error when compared to the predicted tides. This is also true for tides during Typhoon Soulik, although no tidal simulations during Soulik are shown here. The predicted tide is based on harmonic analysis of water level data over a two year period considering 72 constituents, while the simulated tide is based on simulation of 13 tidal constituents over the short operiod of Fanapi. This is the main cause for the discrepancy between the predicted and simulated tides.

\subsection{Waves}

Available wave data is very limited and is only available at a few locations for Typhoon Soulik. Simulated waves using the SWAN model agree well with observed data (Fig. 11).

\subsection{Storm Surge}

Overall, simulated water levels (which include tides and storm surges) based on the large TW grid compare well with the data for both Typhoon Fanapi (Fig. 12) and Typhoon 
Soulik (Fig. 13). The measured surges at all stations, ranging from $0.8-1.2 \mathrm{~m}$ for Fanapi and up to $1.5 \mathrm{~m}$ for Soulik are well represented by the model with the exception that some fine-scale variations are not captured, due partly to inland flooding and rainfall which were not included in this simulation. At Fulong, the peak water level reached $1.3 \mathrm{~m}$, which is somewhere between the peak water levels at Keelung and Longdong where the peak wind occurred.

\subsection{Grid Resolution Effect}

The relatively coarse grid resolution also contributed to the discrepancy between simulated and observed water levels particularly for stations within harbors, channels, and other features that are not well resolved by the model grid. For example, simulated water level during Fanapi in 2010 at Kaohsiung station, located in an enclosed harbor shown in Fig. 14, compares rather poorly with the measured data when the TW grid is used, but improves significantly when the TW-KS grid is used (Fig. 15). As an alternative to using a nested domain this issue could be resolved by locally refining the TW domain at important locations such as harbors near populated areas, etc. The resolution effects are rather localized, however, and stations that are located in the open waters see much smaller improvement (if any) by using the higher resolution model domain.

\subsection{Coastal Inundation}

Additionally, the finer domain (TW-KS) is also superior in predicting the flooded area. The TW-KS simulated (Fig. 16) and observed (Fig. 17) inundation maps, respectively, of the Kaohsiung areas agree quite well qualitatively. Observed inundation in low lying areas and coastal areas are well simulated. However, since the model bathymetry and topography did not contain any river information, inundation near the rivers is not simulated. The simulated inundation map can be significantly improved by inclusion of a watershed-type model into CH3D simulation to better represent run-off due to precipitation.

\subsection{Wave Effect on Surge - Wave Setup}

The observed water level at stations include several components: tides, wind-induiced surge, and wave setup. By extracting tides from the observed water level, the remaining water level is the total surge which includes the wind-induced surge and wave setup, but it is not possible to separate (a)

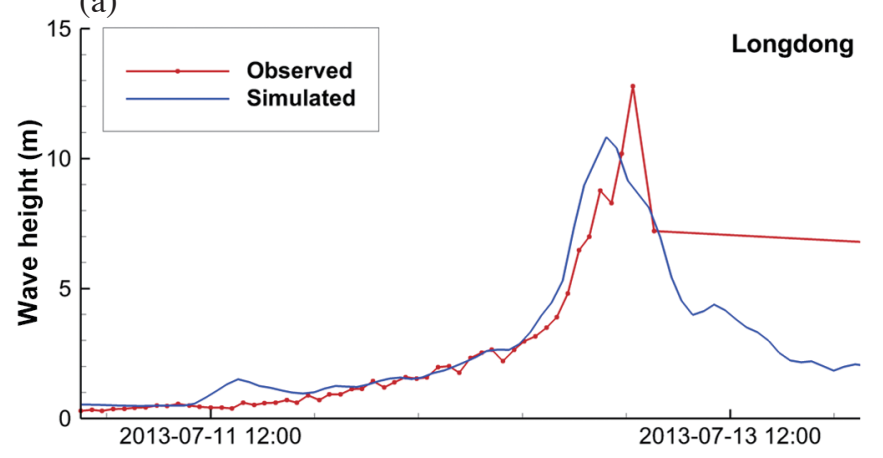

(b)

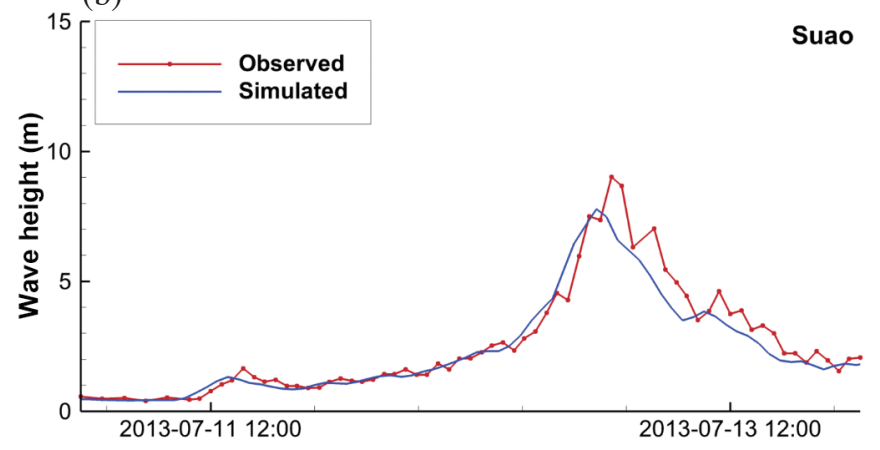

Fig. 11. Simulated vs. measured wave height during Typhon Soulik at (a) Longdong and (b) Suao. (Color online only)

(a)

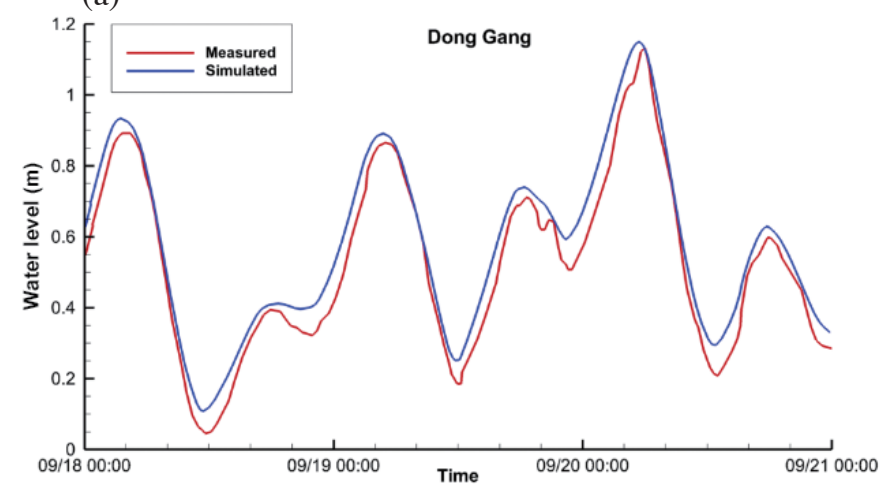

(b)

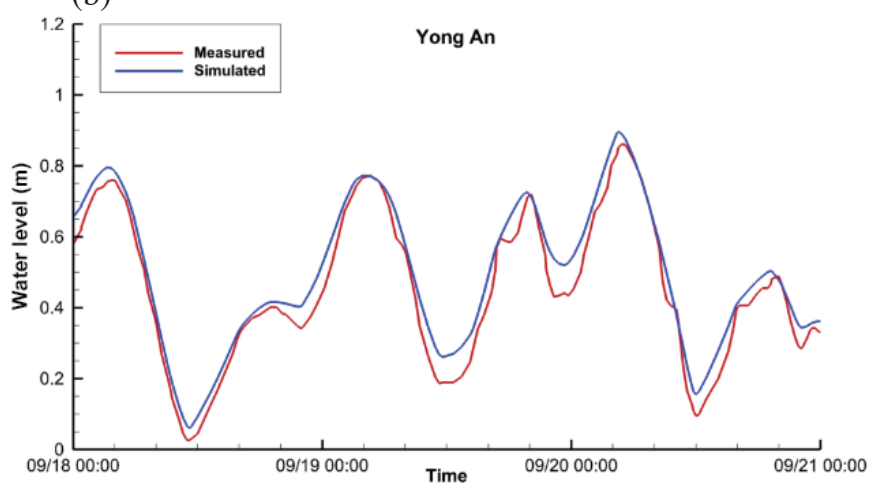

Fig. 12. Simulated water levels during Typhoon Fanapi at (a) Donggang and (b) Yong An using the coupled ACMS in 3-D mode. 

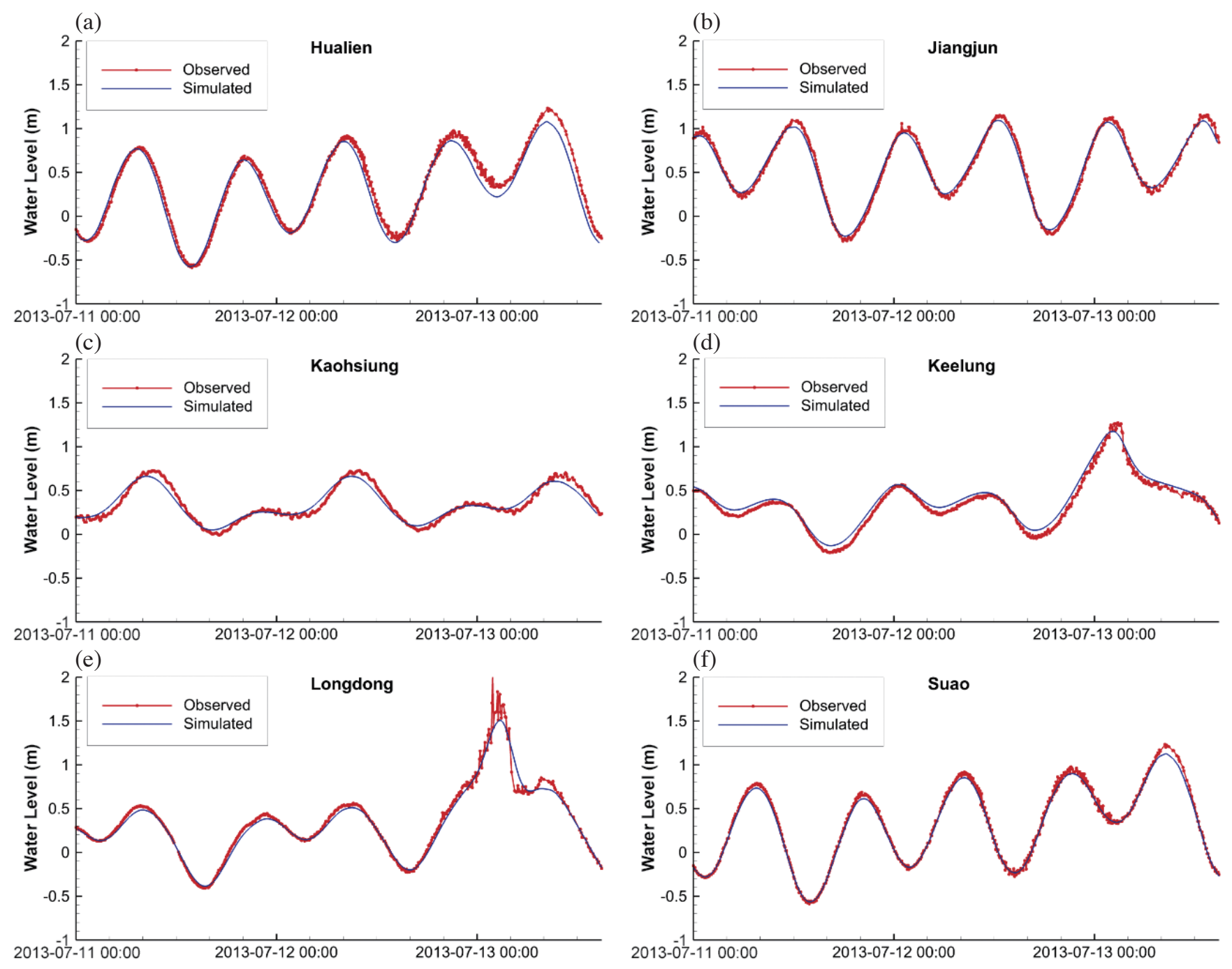

Fig. 13. Simulated water levels during Typhoon Soulik at (a) Hualien, (b) Jiangjun, (c) Kaohsiung, (d) Keelung, (e) Longdong, and (f) Suao using the ACMS in 3-D mode.

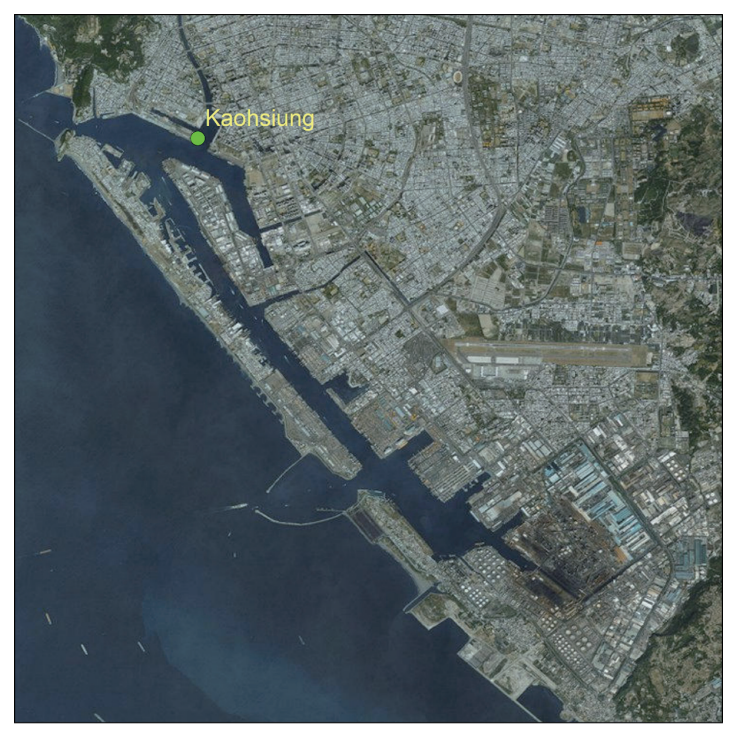

Fig. 14. Location of a water level station at Kaohsiung. (Color online only) 


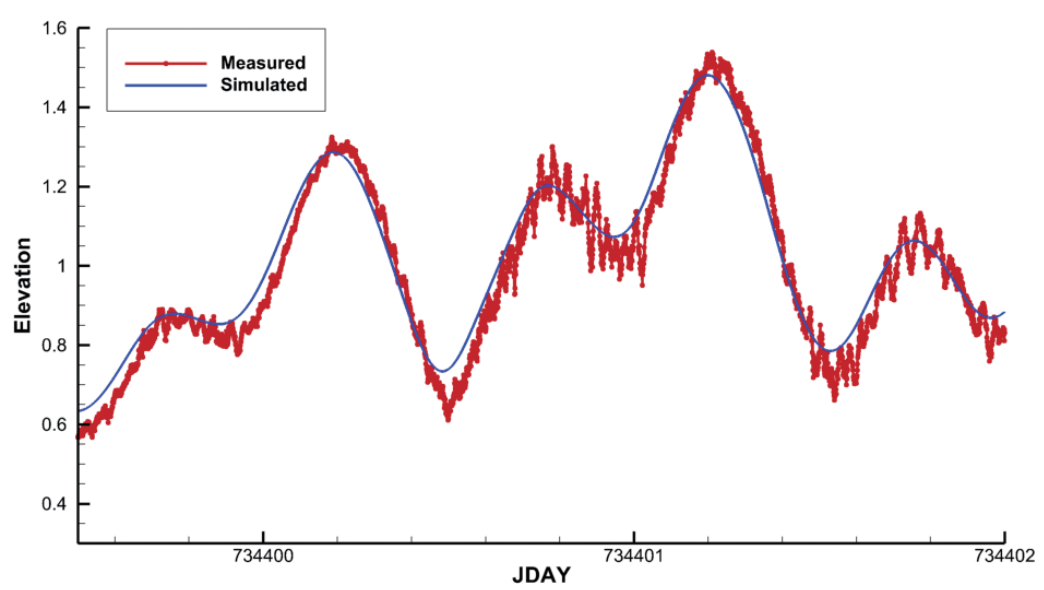

Fig. 15. Comparisons of simulated water level at Kaohsiung station vs. measured data.

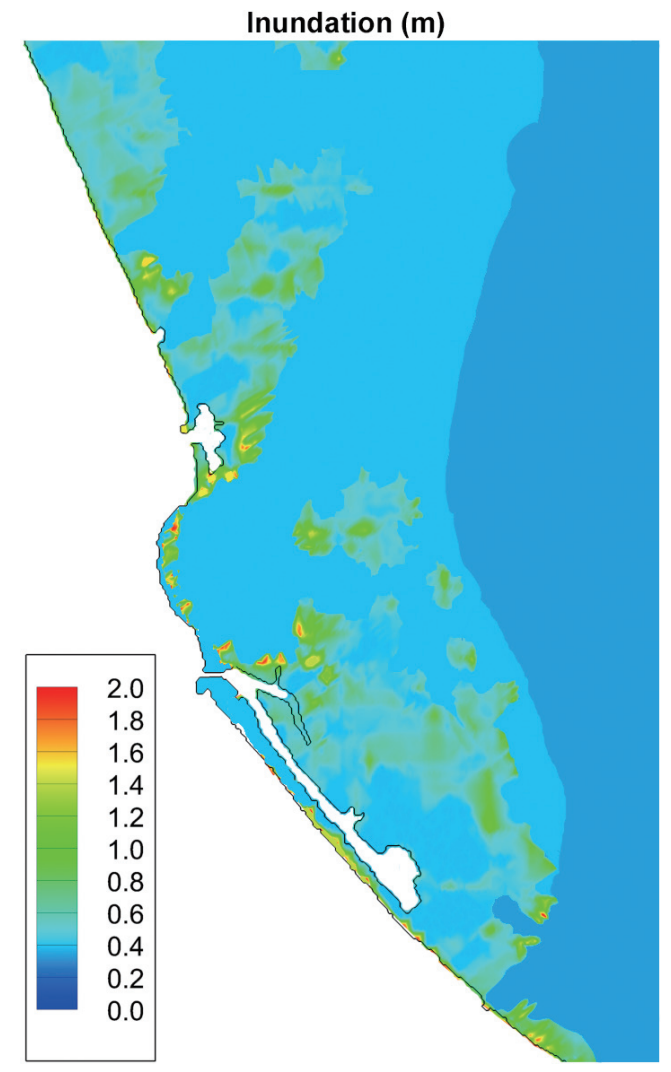

Fig. 16. Simulated inundation map for Kaohsiung area during Typhoon Fanapi.

the total surge into wind-surge and wave setup. The wave setup and wind-surge, however, can be obtained from model simulations. All simulations presented so far were obtained from simulations that include the wind, tides, and waves forcing. Let us call this RUN1. In order to better understand what the total water level consists of, two more model simulations were performed. In RUN2, ACMS is run with wind and tidal forcing but without coupling to the wave model, to
凡那比颱風高雄地區淹水範圍圖

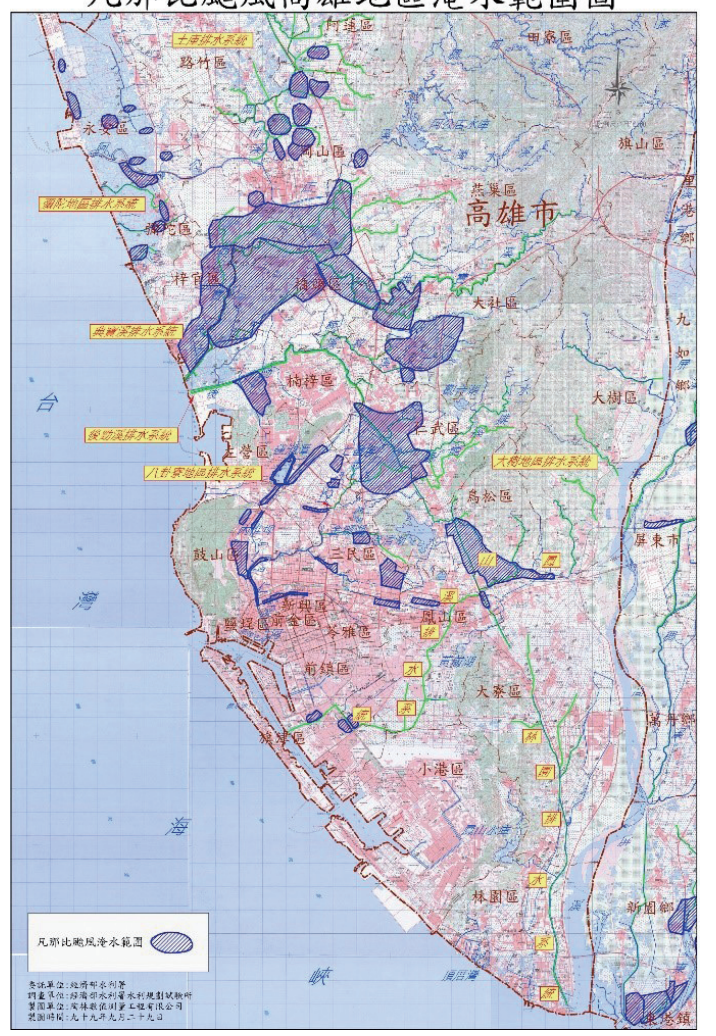

Fig. 17. Map of observed flooding during Fanapi (from MOE 2010). Purple areas are flooded with more than $1 \mathrm{~m}$ water.

determine the water level due to wind and tide. Subtracting the RUN2 results from the RUN1 results yields the wave setup. RUN3 is made by running ACMS with tidal forcing only without any wind and wave effect, to estimate the water level due to tides only. Subtracting the RUN3 results from those of RUN1 yields the total surge which includes windsurge and wave setup, from which pure wind-driven surge can be determined by subtracing the RUN3 results from it. In 
summary, RUN1 - RUN2 = wave setup, RUN1 - RUN3 = total surge, and RUN2 - RUN3 = wind surge. Analysis of these results are presented in Fig. 18 and Table 1 which show that wave setup can contribute to almost $20 \%$ of the total surge at some locations especially at Longdong which is affected by stronger onshore winds and favorable geometry. Longdong station is located in the zone of maximum winds and is shielded by land from west while the winds are from the east which generate very strong waves. It should be noted that the simulated surge and wave setup at all stations, particularly Longdong, are much more accurate than those obtained by Wu (2014), which did not include wave effects, and Liau and Chen (2015), which included one-way surge-wave coupling. Unfortunately, scarce data availability does not allow us to perform an in-depth analysis of simulated waves and wave setup and their variation with a variety of formulations.

\subsection{D vs. 2D Model Results}

In their study of storm surge and waves in the Outerbank area of North Carolina and Chesapeake Bay during Hurricane Isabel, Sheng et al. (2010a) showed that 3D model can provide superior storm surge predictions than $2 \mathrm{D}$ model when wave-current interaction is taken into account. Comparing 2D and 3D model results for Typhoons Fanapi and Soulik shows that a 3D model can provide better estimates, but the difference between 2D and 3D simulated water levels becomes negligible at locations where storm surge and wave setup are small. As shown in Fig. 19, while the 3D simulated surge at Jiangjun station, where the overall surge is very small and wave setup is almost nonexistent, this difference is negligible. At Fulong station the difference is substantial (about $14 \mathrm{~cm}$ ) and the currents just offshore of that station (Fig. 20) show similar patterns to those observed during Hurricane Isabel (Sheng et al. 2010a) where noticeable vertical flow structure exists. The simulated surges at many stations do not differ significantly when 2D and 3D models are used. This is consistent with the findings of Sheng et al. (2010a) which showed that, when 3D model is used, wave-current interactions can produce non-uniform vertical current profiles which result in differences in bottom stress and in turn yields water levels different from 2D simulated water levels. Smaller surge and wave provide weaker interactions and do not result in vertical current structure.

\section{SUMMARY}

Storm surge and coastal inundation over Taiwan has been successfully simulated for Typhoons Fanapi (2010) and Soulik (2013) using ACMS which is based on the CH3D curvilinear-grid hydrodynamics model coupled to SWAN wave model using two (fine and coarser resolution) coastal grids coupled to a coarse $(500 \mathrm{~m})$ model grid. The simulated surge agrees well with observed data for both storms. The

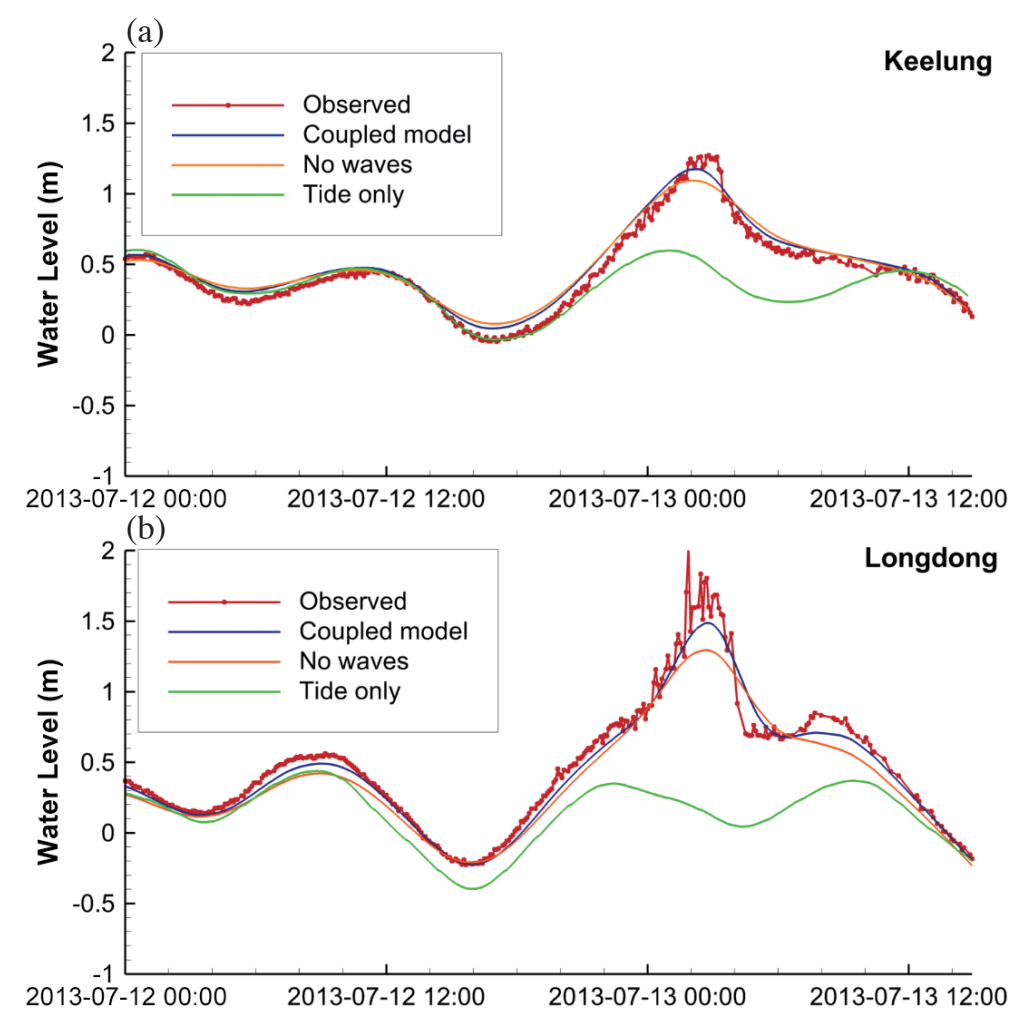

Fig. 18. Comparison of contributions of different components (tides, surge, and wave setup) to the total water level based on simulation of Typhoon Soulik at (a) Keelung and (b) Longdong. 
Table 1. Estimated contributions of different components (astronomical tides, wind-induced surge, and wave setup) to the total water level based on simulation of Typhoon Soulik (2013) at the peak of the simulated water level.

\begin{tabular}{cccc}
\hline Station & Tide $(\mathbf{m})$ & Surge $(\mathbf{m})$ & Wave Setup $(\mathbf{m})$ \\
\hline Hualien & 0.85 & 0.22 & 0.01 \\
Jiangjun & 1.07 & 0.03 & 0.00 \\
Kaohsiung & 0.59 & 0.01 & 0.00 \\
Keelung & 0.55 & 0.53 & 0.08 \\
Longdong & 0.14 & 1.14 & 0.20 \\
Suao & 0.85 & 0.25 & 0.03 \\
\hline
\end{tabular}
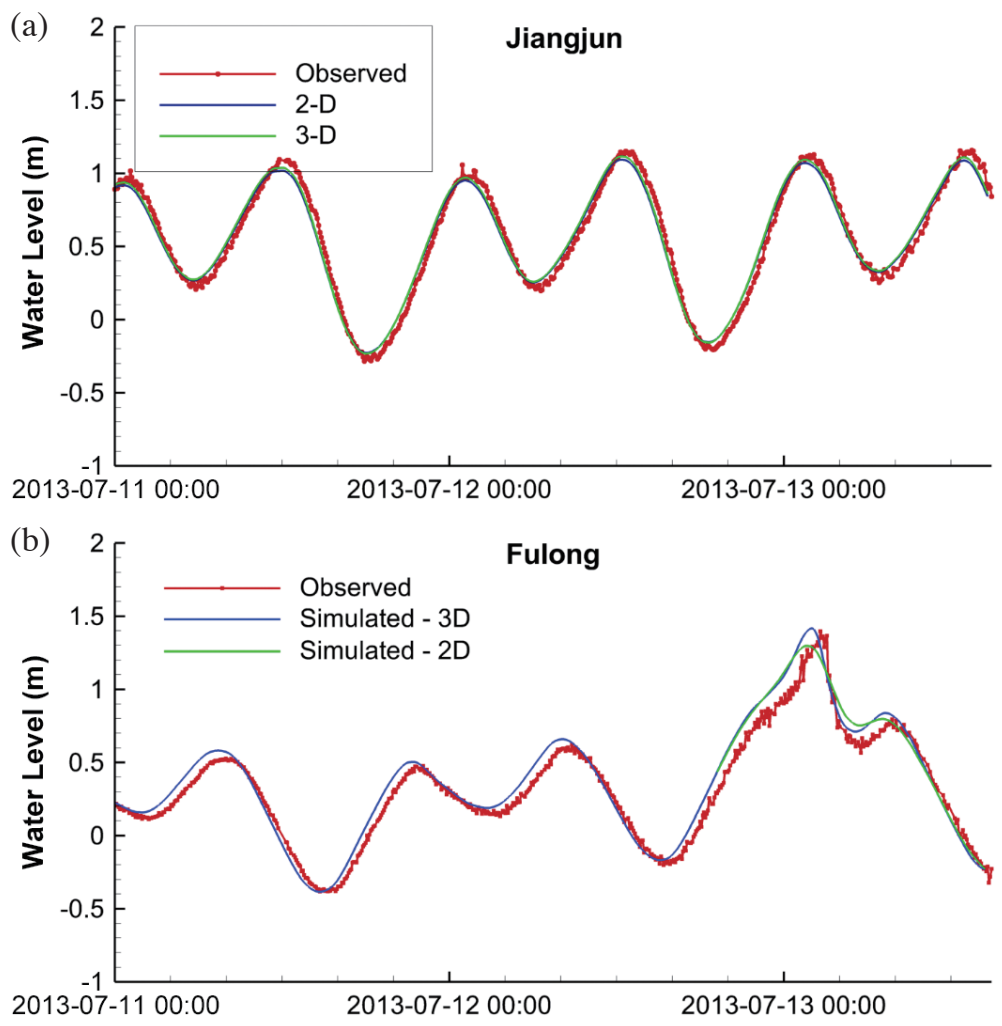

Fig. 19. Comparison of simulated water levels at (a) Jiangjun and (b) Fulong during Typhoon Soulik using 2D and 3D models.

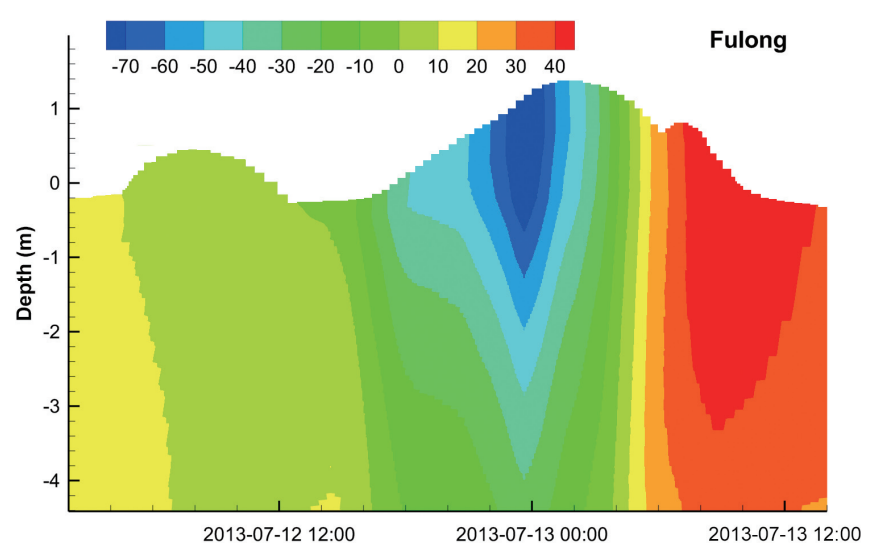

Fig. 20. Simulated cross-shore currents at Fulong station during Typhoon Soulik using the 3D model. Color indicates offshore velocity (negative is onshore) in $\mathrm{cm} \mathrm{s}^{-1}$. 
simulated coastal inundation for Typhoon Fanapi (2010) in Kaohsiung area agrees qualitatively well with observed data, which has considerable uncertainties. Nevertheless, our simulation results show that inundation during Fanapi (heavy rainfall for which was estimated at up to 44 inches in southern Taiwan) in Kaohsiung was caused by both precipitation and coastal surge.

Analysis of astronomical tide, wind-induced surge and wave setup contributions to the total water level shows that wave setup can contribute almost $20 \%$ to the total water level in some areas, which could be part of the reason why previous studies that did not include the effects of waves show poor comparisons with observed data at some locations.

Comparisons of 2D and 3D model simulated water levels and wave setups show that 2D and 3D water level predictions agree well for most stations. However, the 3D model provides better surge estimates at stations where surge and wave setup are more pronounced. Moreover, 3D results revealed significant verticsal flow structure which has implications for search and rescue missions and pollutant transport. Even though more computational resources are required, the 3D model is likely warranted because it provides better water level and current estimates at locations that are more vulnerable and can improve coastal inundation prediction. Verification of these simulated currents could be conducted using data from the recently installed High Frequency Radar system in Taiwan.

Model simulated coastal inundation can be improved by acquiring more and better precipitation data as well as river and flow data or connecting the model to a watershed model which would provide the water runoff which is currently missing. Accurate high-resolution land elevation is very important as well and could be improved. Precipitation in recent typhoons has increased dramatically due most likely to climate change impact. Climate change can also affect the frequency of occurrence and intensity of typhoons (Kang and Elsner 2015), as well as sea level rise, and hence storm surge and coastal inundation. To better protect coastal cities such as Kaohsiung, Tainan, and others along the west coast of Taiwan, it is important to produce risk-based coastal inundation maps which include the storm surge and coastal inundation effects, inland flooding, precipitation, climate change, and sea level rise.

Acknowledgements We thank Prof. Guan-Yu Chen of NSYSU for providing the digital water level data from Kaohsiung during Fanapi, and Mr. Lin from the Ministry of Economy for providing the Fanapi investigative report. We also thank the thorough reviews of this paper by Two Anonymous Reviewers and S. Jan.

\section{REFERENCES}

Barron, C. N., A. B. Kara, H. E. Hurlburt, C. Rowley, and
L. F. Smedstad, 2004: Sea surface height predictions from the Global Navy Coastal Ocean Model during 1998-2001. J. Atmos. Ocean. Technol., 21, 1876-1893, doi: 10.1175/JTECH-1680.1. [Link]

Bleck, R. and S. G. Benjamin, 1993: Regional weather prediction with a model combining terrain-following and isentropic coordinates. Part I: Model description. Mon. Weather Rev., 121, 1770-1785, doi: 10.1175/1520-049 3(1993) $121<1770:$ RWPWAM $>2$.0.CO;2. [Link]

Chen, C., G. Cowles, and R. C. Beardsley, 2006: An unstructured grid, finite-volume coastal ocean model. FVCOM User Manual, $2^{\text {nd }}$ edition, SMAST/UMASSD Report TR-06-0602, 315 pp.

Davis, J. R. and Y. P. Sheng, 2003: Development of a parallel storm surge model. Int. J. Numer. Methods Fluids, 42, 549-580, doi: 10.1002/fld.531. [Link]

DiNapoli, S. M., M. A. Bourassa, and M. D. Powell, 2012: Uncertainty and intercalibration analysis of $\mathrm{H}^{*}$ Wind. J. Atmos. Ocean. Technol., 29, 822-833, doi: 10.1175/ JTECH-D-11-00165.1. [Link]

Holland, G. J., 1980: An analytic model of the wind and pressure profiles in hurricanes. Mon. Weather Rev., 108, 1212-1218, doi: 10.1175/1520-0493(1980)108<1 212:AAMOTW>2.0.CO;2. [Link]

Hsiao, L. F., C. S. Liou, T. C. Yeh, Y. R. Guo, D. S. Chen, K. N. Huang, C. T. Terng, and J. H. Chen, 2010: A vortex relocation scheme for tropical cyclone initialization in advanced research WRF. Mon. Weather Rev., 138, 3298-3315, doi: 10.1175/2010MWR3275.1. [Link]

Hsiao, L. F., D. S. Chen, Y. H. Kuo, Y. R. Guo, T. C. Yeh, J. S. Hong, C. T. Fong, and C. S. Lee, 2012: Application of WRF 3DVAR to operational typhoon prediction in Taiwan: Impact of outer loop and partial cycling approaches. Weather Forecast., 27, 1249-1263, doi: 10.1175/WAF-D-11-00131.1. [Link]

IPET (Interagency Performance Evaluation Task Force), 2006: Performance Evaluation of the New Orleans and Southeast Louisiana Hurricane Protection System: Draft Final Report of the Interagency Performance Evaluation Task Force, US Army Corps of Engineers, USA.

Jelesnianski, C. P., J. Chen, and W. A. Shaffer, 1992: SLOSH: Sea, Lake, and Overland Surges from Hurricanes, NOAA Technical Report NWS 48, 71 pp.

JTWC (Joint Typhoon Warning Center), 2010: Tropical Storm 12W (Fanapi) Warning NR 007, Joint Typhoon Warning Center.

JTWC (Joint Typhoon Warning Center), 2011: Joint Typhoon Warning Center Mission Statement, United States Navy, Archived from the original on July 26, 2007.

JTWC (Joint Typhoon Warning Center), 2014: Significant Tropical Weather Outlook for the Western and South Pacific Oceans, Joint Typhoon Warning Center, 201009-13. 
Kang, N. Y. and J. B. Elsner, 2015: Trade-off between intensity and frequency of global tropical cyclones. Nat. Clim. Change, 5, 661-664. doi:10.1038/nclimate2646. [Link]

Ko, D. S., S. Y. Chao, C. C. Wu, I. I. Lin, and S. Jan, 2016: Impacts of tides and Typhoon Fanapi (2010) on seas around Taiwan. Terr. Atmos. Ocean. Sci., 27, 261-280, doi: 10.3319/TAO.2015.10.28.01(Oc). [Link]

Kurihara, Y., R. E. Tuleya, and M. A. Bender, 1998: The GFDL Hurricane Prediction System and its performance in the 1995 hurricane season. Mon. Weather Rev., 126, 1306-1322, doi: 10.1175/1520-0493(1998) 126<1306:TGHPSA > 2.0.CO;2. [Link]

Lapetina, A. and Y. P. Sheng, 2015: Simulating complex storm surge dynamics: Three-dimensionality, vegetation effect, and onshore sediment transport. J. Geophys. Res., 120, 7363-7380, doi: 10.1002/2015JC010824. [Link]

Lee, J., Y. Chiu, C. Liu, C. Su, M. Cheng, J. Lee, L. Tu, and C. Shieh, 2015: Enhancement of Marine Meteorology Simulation Techniques for System Maintenance and Operation in Taiwan Major Habors, Harbor \& Marine Technology Center, Institute of Transportation, Ministry of Transportation and Communications, MOTCIOT-103-H3DC001.

Liau, J. M. and S. H. Chen, 2015: Effect of the wave set-up on the estimation of storm surge in the coastal waters. Taiwan Water Conservancy, 63, 83-92.

Longuet-Higgins, M. S. and R. W. Stewart, 1962: Radiation stress and mass transport in gravity waves, with application to 'surf beats'. J. Fluid Mech., 13, 481-504, doi: 10.1017/S0022112062000877. [Link]

Longuet-Higgins, M. S. and R. W. Stewart, 1964: Radiation stresses in water waves; a physical discussion, with applications. Deep Sea Res. Oceanogr. Abstr., 11, 529562, doi: 10.1016/0011-7471(64)90001-4. [Link]

Luettich, R. A., J. J. Westerink, and N. W. Scheffner, 1992: ADCIRC: An Advanced Three-Dimensional Circulation Model for Shelves, Coasts, and Estuaries; Report 1: Theory and Methodology of ADCIRC-2DDI and ADCIRC-3DL, Technical Report DRP-92-6, US Army Corps of Engineer, Washington, D.C., 137 pp.

Mellor, G. L., 2008: The depth-dependent current and wave interaction equations: A revision. J. Phys. Oceanogr., 38, 2587-2596, doi: 10.1175/2008JPO3971.1. [Link]

MOE (Ministry of Economy), 2010: Investigative report of coastal flooding during typhoon Fanapi, Taiwan, R.O.C.

NAS (National Academy of Sciences), 2009: Mapping the Zone: Improving Flood Map Accuracy, National Academies Press, Washington, D.C., 136 pp, doi: 10.17226/12573. [Link]

Peng, M., L. Xie, and L. J. Pietrafesa, 2004: A numerical study of storm surge and inundation in the Croatan-Al-
bemarle-Pamlico Estuary System. Estuar. Coast. Shelf Sci., 59, 121-137, doi: 10.1016/j.ecss.2003.07.010. [Link]

Ris, R. C., L. H. Holthuijsen, and N. Booij, 1999: A third-generation wave model for coastal regions: 2 . Verification. J. Geophys. Res., 104, 7667-7681, doi: 10.1029/1998JC900123. [Link]

Rosmond, T. E., 1992: The design and testing of the Navy Operational Global Atmospheric Prediction System. Weather Forecast., 7, 262-272, doi: 10.1175/1520-043 4(1992)007<0262:TDATOT>2.0.CO;2. [Link]

Sheng, Y. P., 1987: On modeling three-dimensional estuarine and marine hydrodynamics. Elsevier Oceanography Series, 45, 35-54, doi: 10.1016/S04229894(08)70441-0. [Link]

Sheng, Y. P., 1990: Evolution of a three-dimensional curvilinear-grid hydrodynamic model for estuaries, lakes and coastal waters: CH3D. Estuarine and Coastal Modeling I, ASCE, 40-49.

Sheng, Y. P., 2015: Evaluation of an Integrated Taiwan Coastal Hazard Forecasting System, Interim Report for Central Weather Bureau.

Sheng, Y. P. and T. Liu, 2011: Three-dimensional simulation of wave-induced circulation: Comparison of three radiation stress formulations. J. Geophys. Res., 116, C05021, doi: 10.1029/2010JC006765. [Link]

Sheng, Y. P. and C. Villaret, 1989: Modeling the effect of suspended sediment stratification on bottom exchange processes. J. Geophys. Res., 94, 14429-14444, doi: 10.1029/JC094iC10p14429. [Link]

Sheng, Y. P., V. A. Paramygin, V. Alymov, and J. R. Davis, 2006: A real-time forecasting system for hurricane induced storm surge and coastal flooding. Estuarine and Coastal Modeling (2005), 585-602, doi: 10.1061/40876(209)34. [Link]

Sheng, Y. P., V. A. Paramygin, Y. Zhang, and J. R. Davis, 2008: Recent enhancements and applications of an integrated storm surge modeling system: CH3D-SSMS. Estuarine and Coastal Modeling (2007), 879-892, doi: 10.1061/40990(324)47. [Link]

Sheng, Y. P., V. Alymov, and V. A. Paramygin, 2010a: Simulation of storm surge, wave, currents, and inundation in the Outer Banks and Chesapeake Bay during Hurricane Isabel in 2003: The importance of waves. J. Geophys. Res., 115, C04008. doi: 10.1029/2009JC005402. [Link]

Sheng, Y. P., Y. Zhang, and V. A. Paramygin, 2010b: Simulation of storm surge, wave, and coastal inundation in the Northeastern Gulf of Mexico region during Hurricane Ivan in 2004. Ocean Model., 35, 314-331. doi: 10.1016/j.ocemod.2010.09.004. [Link]

Sheng, Y. P., J. R. Davis, R. Figueiredo, B. Liu, H. Liu, R. Luettich, V. A. Paramygin, R. Weaver, R. Weisberg, L. Xie, and L. Zheng, 2012: A regional testbed for 
storm surge and coastal inundation models-An overview. Estuarine and Coastal Modeling (2011), doi: 10.1061/9780784412411.00028. [Link]

Skamarock, W. C., J. B. Klemp, J. Dudhia, D. O. Gill, D. M. Barker, W. Wang, and J. G. Powers, 2005: A Description of the Advanced Research WRF Version 2, NCAR Technical Note NCAR/TN-468+STR, doi: 10.5065/ D6DZ069T. [Link]

Tutak, B. and Y. P. Sheng, 2011: Effect of tropical cyclones on residual circulation and momentum balance in a subtropical estuary and inlet: Observation and simulation. J. Geophys. Res., 116, C06014, doi: 10.1029/2011JC006988. [Link]

Wilson, B. W., 1960: Note on surface wind stress over wa- ter at low and high wind speeds. J. Geophys. Res., $\mathbf{6 5}$, 3377-3382, doi: 10.1029/JZ065i010p03377. [Link]

Wu, C., 2014: Development of a Forecasting Model for Near Coast Storm Surge and Coastal Inundation in Taiwan, Progress Report fo Central Weather Bureau, MOTC-CWB-103-O-02.

Xie, L., S. Bao, L. J. Pietrafesa, K. Foley, and M. Fuentes, 2006: A real-time hurricane surface wind forecasting model: Formulation and verification. Mon. Weather Rev., 134, 1355-1370, doi: 10.1175/MWR3126.1. [Link]

Yu, C. S., M. Marcus, and J. Monbaliu, 1994: Numerical modeling of storm surges along the Belgium coast. In: Peters, A. (Ed.), Computational Methods in Water Resouces X, Kluwer Academic, Dordrecht, 1331-1338. 